\title{
DIREITO AO SILÊNCIO: BREVE NOTÍCIA DA JURISPRUDÊNCIA NORTE-AMERICANA
}

RESUMO: O direito ao silêncio não pode ser confundido com o direito de não produzir qualquer prova contra si mesmo. O direito ao silêncio tem alcance mais restrito, pois se relaciona ao ato de falar ou equivalente. A Constituição brasileira tem redação muito semelhante, no ponto, à Constituição norte-americana, de alcance mais restrito. A jurisprudência da Suprema Corte norteamericana confere interpretação restritiva ao texto constitucional americano, permitindo por exemplo o uso de amostras de sangue colhidas contra a vontade do acusado. A obrigação de entregar livros e papéis fiscais e comerciais não importa violência nem ofensa à privacidade e, portanto, não viola o direito constitucional ao silêncio.

Constitucional - Processo penal - Tributário - Direito ao silêncio - Jurisprudência - Suprema Corte norte-americana

\section{Autor: Cristiano de Jesus Pereira Nascimento.}

Juiz Federal. Mestrando em Filosofia do Direito PUC/SP

http://revistasapereaude.org/index.php/edicoes/ano-5-volume-3-outubro-2016

D.O.I: 10.20523/sapereaude-ano5-vol-3-pg-1-25 


\section{INTRODUÇÃO.}

Para que os agentes do Estado possam aplicar a lei é necessário, antes, uma pesquisa dos fatos. Dito de outra forma: "para que o processo de positivação se realize, necessário se faz o perfeito quadramento do fato à previsão normativa abstrata". ${ }^{1}$

A premissa filosófica de que a verdade absoluta e objetiva é uma idéia ilusória, pois a realidade do mundo, em si, não é apreensível pela linguagem, não inibe a conclusão de que o processo e as atividades dos operadores do direito devem estar ancorados em fatos que tenham efetivamente ocorrido no mundo sensível. Agride o senso comum uma decisão que se baseie num fato reconhecidamente inexistente, ou que desconsidere fatos reconhecidamente existentes. A não ser que a apuração desses fatos, mesmo que verdadeiros, viole igualmente os valores morais, sociais, jurídicos.

Como ressalta Michele Taruffo, uma das condições para que se possa considerar justa uma decisão é que ela se ampare numa apuração verdadeira dos fatos da causa, visto que nenhuma decisão é justa se se fundar em fatos equivocados. ${ }^{2}$ Para Taruffo, o processo pode ser considerado justo se for sistematicamente orientado a fazer com que se estabeleça a verdade dos fatos relevantes para a decisão. ${ }^{3}$

No entanto, a pesquisa dos fatos deve ser feita mediante procedimento razoável, sensato. Não interessa, ao Estado, a verdade a qualquer custo. Essa pesquisa, ou seja, a produção de provas, deve orientar-se por valores e deve obedecer ao procedimento previsto em lei. Repugna à

\footnotetext{
${ }^{1}$ TOMÉ, Fabiana del Padre. A prova no direito tributário. $3^{\mathrm{a}}$ ed. São Paulo: Noeses, 2012, p. 360.

2 TARUFFO, Michele. Uma simples verdade: o juiz e a construção dos fatos. São Paulo: Marcial Pons, 2012 , p. 142.

${ }^{3}$ TARUFFO, p. 143.
}

http://revistasapereaude.org/index.php/edicoes/ano-5-volume-3-outubro-2016 
consciência civilizada, por exemplo, que o Estado encontre a informação verdadeira mediante a tortura de um ser humano. É do mesmo mestre italiano a advertência: "dificilmente se poderia aceitar como justa uma decisão produzida em um processo em que tenham sido violadas garantias fundamentais". ${ }^{4}$

Nessa ordem de idéias, o princípio da não autoincriminação (nemo tenetur se detegere) representa uma relevante limitação à produção probatória no processo penal. O princípio compõe a consciência jurídica moderna de que o Estado tem interesse em apurar e enunciar a verdade dos fatos, da forma mais fidedigna possível, mas tal apuração não deve forçar o acusado a se autoincriminar.

O presente artigo pretende visitar a jurisprudência da Suprema Corte estadunidense acerca do direito ao silêncio, enfatizando as diferenças marcantes entre o alcance desse direito subjetivo nos Estados Unidos e no Brasil.

\section{DIREITO AO SILÊNCIO E DIREITO DE NÃO PRODUZIR PROVA CONTRA SI MESMO.}

Algumas distinções preliminares são necessárias. É possível distinguir conceitualmente o "direito ao silêncio" e o "direito a não produzir prova contra si mesmo". O direito ao silêncio pode ser considerado como o direito do preso de permanecer calado, de não ser obrigado a confessar o crime. Por sua vez, o direito de não produzir prova contra si mesmo é mais amplo, assegurando que o acusado não precisa colaborar com a própria condenação, seja através de sua confissão, seja através de qualquer outro meio de prova.

O direito ao silêncio, consagrado expressamente na Constituição da República, não implica automaticamente no direito mais amplo de não produzir qualquer prova contra si mesmo. Na lição

${ }^{4}$ TARUFFO, p. 142.

http://revistasapereaude.org/index.php/edicoes/ano-5-volume-3-outubro-2016

D.O.I: $10.20523 /$ sapereaude-ano5-vol-3-pg-1-25 
de João Claudio Couceiro seria, antes, uma especificação desse direito mais amplo de todo homem, a não colaborar na produção de qualquer prova que possa vir a prejudicá-lo. ${ }^{5}$

Questão importante, portanto, é saber se o direito positivo brasileiro alberga proteção apenas às declarações orais do investigado ou se tem alcance amplo, repercutindo em qualquer tipo de prova, e não apenas no interrogatório do réu ou acusado.

Em primeiro lugar, é preciso ressaltar que essa indagação não tem uma resposta óbvia. A opinião de que a Constituição brasileira respalda um direito genérico e abrangente de não produzir qualquer tipo de prova que implique autoincriminação, é razoável e bem fundada, mas está longe de ser evidente por si mesma.

Basta dizer, para afastar qualquer veleidade de premissa óbvia, que a jurisprudência norteamericana, que tem se debruçado sobre o tema ao longo de dois séculos, jamais emprestou à garantia constitucional prevista na Quinta Emenda um alcance que vemos no Brasil, tanto na doutrina quanto na jurisprudência, inclusive do Supremo Tribunal Federal.

\section{A BASE NORMATIVA DO DIREITO AO SILÊNCIO NOS ESTADOS UNIDOS}

A Suprema Corte norte-americana faz uma distinção clara entre o direito ao silêncio e o direito a não produzir qualquer tipo de prova contra si. Para o direito americano, a Constituição assegura apenas o direito que tem a pessoa de não ser testemunha contra si mesma. Outros tipos de prova não são alcançadas pela garantia constitucional.

A base dessa interpretação é a própria redação do dispositivo constitucional. Com efeito, a Quinta Emenda possui o seguinte texto:

${ }^{5}$ COUCEIRO, João Claudio. A garantia constitucional do direito ao silêncio. São Paulo: Editora Revista dos Tribunais, 2004, p. 152.

http://revistasapereaude.org/index.php/edicoes/ano-5-volume-3-outubro-2016

D.O.I: $10.20523 /$ sapereaude-ano5-vol-3-pg-1-25 
No person shall be held to answer for a capital, or otherwise infamous crime, unless on a presentment or indictment of a Grand Jury, except in cases arising in the land or naval forces, or in the Militia, when in actual service in time of War or public danger; nor shall any person be subject for the same offence to be twice put in jeopardy of life or limb; nor shall be compelled in any criminal case to be a witness against himself, nor be deprived of life, liberty, or property, without due process of law; nor shall private property be taken for public use, without just compensation.

O direito ao silêncio pode ser extraído da seguinte passagem: "nor shall be compelled in any criminal case to be a witness against himself". Numa tradução livre: não deve ser forçada, em qualquer processo criminal, a ser testemunha contra si mesma. $\mathrm{O}$ texto é tão restritivo quanto o inciso LXIII do art. $5^{\circ}$ da Constituição de 1988, que se limita a dizer que o preso tem direito de permanecer calado.

A redação da Declaração da Virgínia possuía texto que autoriza uma interpretação mais ampla, pois ostentava, em seu artigo oitavo, a seguinte redação: "(...) nor can he be compelled to give evidence against himself; (...)". Numa tradução livre: "nenhum homem pode ser forçado a oferecer prova contra si mesmo". ${ }^{6}$

No entanto, o fato é que o texto da Constituição norte-americana, em sua Quinta Emenda, foi menos amplo. A Suprema Corte daquele país tem dado consequiência à opção do constituinte, limitando a garantia à não-autoincriminação àquelas hipóteses nas quais exista algum depoimento oral ou atividade que tenha alguma equivalência com o depoimento oral.

\footnotetext{
${ }^{6} \mathrm{O}$ inteiro teor do artigo oitavo é o seguinte: "That in all capital or criminal prosecutions a man hath a right to demand the cause and nature of his accusation, to be confronted with the accusers and witnesses, to call for evidence in his favor, and to a speedy trial by an impartial jury of twelve men of his vicinage, without whose unanimous consent he cannot be found guilty; nor can he be compelled to give evidence against himself; that no man be deprived of his liberty, except by the law of the land or the judgment of his peers"
}

http://revistasapereaude.org/index.php/edicoes/ano-5-volume-3-outubro-2016

D.O.I: 10.20523/sapereaude-ano5-vol-3-pg-1-25 


\section{OS CRIMES DE TRÂNSITO E O DIREITO DE NÃO PRODUZIR PROVA CONTRA SI, NO BRASIL E}

NOS ESTADOS UNIDOS.

A distinção entre o direito ao silêncio e o direito de não produzir prova contra si fica muito evidente quando se constata a grande diferença entre o direito norte-americano e o direito brasileiro no tratamento dos crimes de trânsito, mais especificamente na produção da prova nos crimes de trânsito.

No Brasil, a negativa de soprar o bafômetro talvez seja a expressão mais popularizada do direito de não produzir prova contra si. A recusa em submeter-se ao teste do bafômetro incorporouse à cultura popular. Qualquer motorista brasileiro sabe que não precisa sujeitar-se ao teste de alcoolemia, soprando no etilômetro (bafômetro). Se o motorista se recusa ao teste, o que resta à autoridade é tentar caracterizar a embriaguez mediante a descrição de sinais exteriores. Contudo, nenhuma medida invasiva é cogitada pela lei e tampouco pela jurisprudência.

Com efeito, o art. 306 da Lei 9.503/97 (Código de Trânsito Brasileiro) tipifica a conduta de "conduzir veículo automotor com capacidade psicomotora alterada em razão da influência de álcool ou de outra substância psicoativa que determine dependência". A lei considera a presença de embriaguez se houver concentração de álcool por litro de sangue igual ou superior a "6 decigramas de álcool por litro de sangue", bem como igual ou superior a "0,3 miligrama de álcool por litro de ar alveolar". Não havendo a possibilidade de aferição precisa desses níveis de intoxicação, a lei admite que a embriaguez pode ser aferida por sinais que indiquem a alteração da capacidade psicomotora.

A lei de trânsito não impõe ao motorista a colheita de material para aferição de seu estado psicomotor. Ao contrário, prevê expressamente conseqüências administrativas para o motorista que

http://revistasapereaude.org/index.php/edicoes/ano-5-volume-3-outubro-2016 D.O.I: $10.20523 /$ sapereaude-ano5-vol-3-pg-1-25 
se recusa a se submeter ao procedimento fiscalizatório, nos termos do $\S 3^{\circ}$ do art. 277 do mesmo diploma legal:

Art. 277. O condutor de veículo automotor envolvido em acidente de trânsito ou que for alvo de fiscalização de trânsito poderá ser submetido a teste, exame clínico, perícia ou outro procedimento que, por meios técnicos ou científicos, na forma disciplinada pelo Contran, permita certificar influência de álcool ou outra substância psicoativa que determine dependência.

$$
(\ldots)
$$

$\S$ 3o Serão aplicadas as penalidades e medidas administrativas estabelecidas no art. 165 deste Código ao condutor que se recusar a se submeter a qualquer dos procedimentos previstos no caput deste artigo.

O art. 165 do código de trânsito, por sua vez, prevê as seguintes penalidades administrativas: a) infração gravíssima, com pontuação correspondente na carteira de habilitação; b) multa (dez vezes); c) suspensão do direito de dirigir por 12 meses; d) recolhimento do documento de habilitação; e) retenção do veículo.

Nos Estados Unidos, os crimes de trânsito não estão previstos em diploma de abrangência nacional, pois cada Estado tem competência para editar legislação sobre o assunto. No entanto, algumas questões já estão sedimentadas e recebem tratamento uniforme em razão dos precedentes formulados pela Suprema Corte daquele país. 
A análise dos quatro precedentes seguintes serve para dar notícia do grau de invasão, até mesmo corporal, que o direito norte-americano admite quando se trata de produção probatória em processo criminal. É imensa a diferença entre o que se considera autoincriminação no Brasil e nos Estados Unidos, país que vem examinando durante dois séculos esse direito.

Já está consolidado, por exemplo, o entendimento de que é possível, nos crimes de trânsito ou que envolvam acidente de trânsito, a extração de sangue do motorista para aferição de eventual consumo de álcool, quando o motorista se negue a realizar o teste do bafômetro.

\title{
4.1. Breithaupt v. Abram (1957)
}

Em 1957, no caso Breithaupt v. Abram, a Suprema Corte americana julgou o seguinte caso (tradução livre):

\begin{abstract}
"um indivíduo, enquanto dirigia uma pick-up numa rodovia estadual, envolveu-se numa colisão que resultou na morte de três pessoas e em sérios
\end{abstract} ferimentos nele. Enquanto ele estava inconsciente na sala de emergência do hospital, detectou-se forte cheiro de bebida em seu hálito, e o patrulheiro estadual solicitou que uma amostra de sangue fosse retirada. Um clínico, utilizando uma agulha hipodérmica, colheu uma amostra de sangue que, após análise laboratorial, continha cerca de 0,17\% de álcool. Em seguida, esse indivíduo foi condenado por uma Corte estadual por homicídio culposo. No julgamento, a evidência do exame de sangue, juntamente com o depoimento do perito de que a pessoa com $0,17 \%$ de álcool estava sob influência de intoxicação por bebida, foi admitida mesmo diante da objeção do acusado". ${ }^{7}$

\footnotetext{
${ }^{7}$ A ementa do acórdão, no original: "Petitioner, while driving a pickup truck on a state highway, was involved in a collision which resulted in the deaths of three persons and his serious injury. While he was lying unconscious in the emergency room of a hospital, the smell of liquor was detected on his breath, and a state patrolman requested that a

http://revistasapereaude.org/index.php/edicoes/ano-5-volume-3-outubro-2016

D.O.I: 10.20523/sapereaude-ano5-vol-3-pg-1-25
} 
A Suprema Corte considerou, numa votação por 6x3, que a realização do exame de sangue por um médico capacitado não configurava uma conduta repugnante à consciência jurídica, nem um método de obter evidência que ofendesse o senso de justiça. E mais, que o direito do indivíduo à inviolabilidade de tal invasão do corpo, como a que está presente num exame de sangue seguro, é largamente suplantada pelo valor que essa prova tem para a solução de controvérsias relativas à direção sob influência do álcool.

Em outras palavras, o órgão de cúpula ponderou o grau de invasão dessa prova e o grau de efetividade e importância dela para a conclusão sobre o cometimento da infração, concluindo que a utilização de amostra de sangue, mesmo contra a vontade do acusado, constituía uma prova válida.

\subsection{Schmerber v. California (1966)}

Em 1966, a Corte estadunidense voltou ao tema no caso Schmerber v. California. A diferença entre o caso Breithaupt v. Abram e o caso Schmerber é a circunstância de que, no primeiro, o indivíduo estava inconsciente, enquanto no segundo ele estava lúcido e se opôs claramente à realização do teste. Em Schmerber v. California os fatos sob julgamento eram os seguintes (tradução livre):

\footnotetext{
"Um indivíduo foi hospitalizado após um acidente envolvendo um automóvel que ele aparentemente estava dirigindo. Um policial sentiu o cheiro de bebida no hálito do indivíduo e observou outros sintomas de bebedeira na cena do acidente e no hospital, mantendo-o sob custódia, informando-o de que ele tinha direito a um advogado, de que ele poderia permanecer calado, e de que
}

sample of his blood be taken. An attending physician, using a hypodermic needle, drew a blood sample which, on laboratory analysis, contained about $.17 \%$ alcohol. Thereafter, petitioner was convicted in a state court voluntary manslaughter. At his trial, the evidence of the blood test, together with expert testimony that a person with.17\% alcohol in his blood was under the influence of intoxicating liquor, was admitted over petitioner's objection" (https://supreme.justia.com/cases/federal/us/352/432/). 
tudo que ele dissesse poderia ser usado contra ele. Sob a supervisão do policial, um clínico colheu uma amostra de sangue do indivíduo, apesar de sua recusa. Um relatório da análise química do sangue, a qual indicava intoxicação, foi admitida como prova no julgamento do indivíduo por dirigir embriagado, a despeito da objeção do indivíduo. Ele foi condenado e a condenação foi confirmada pela corte de apelação, que rejeitou seus argumentos de violação ao devido processo, ao direito de não autoincriminação, ao direito a assistência jurídica, e ao direito de não ser submetido a buscas e apreensões irrazoáveis". ${ }^{8}$

A Suprema Corte decidiu o caso numa votação mais apertada, 5 x 4, mas manteve a conclusão de que era possível utilizar como prova, em processo penal, uma amostra de sangue colhida contra a vontade do acusado. O redator do acórdão foi o juiz William Brennan, que foi acompanhado por Clark, Harlan, Stewart e White. Compuseram a minoria os juízes Warren (Chief Justice), Black, Douglas e Fortas. Não é irrelevante observar que o juiz Brennan alcançou projeção por ser, na Suprema Corte, um representante do campo liberal e progressista do direito. ${ }^{9}$

É interessante destacar dois fundamentos utilizados pela Corte americana: a) o privilégio contra a autoincriminação não é aplicável a um caso como esse, no qual não há sequer uma sombra de compulsoriedade para testemunhar contra si mesmo, ou de qualquer forma fornecer ao Estado prova de natureza testemunhal ou comunicativa; b) o teste escolhido para medir o nível de álcool no

\footnotetext{
${ }^{8}$ A ementa, no original: "Petitioner was hospitalized following an accident involving an automobile which he had apparently been driving. A police officer smelled liquor on petitioner's breath and noticed other symptoms of drunkenness at the accident scene and at the hospital, placed him under arrest, and informed him that he was entitled to counsel, that he could remain silent, and that anything he said would be used against him. At the officer's direction, a physician took a blood sample from petitioner despite his refusal on advice of counsel to consent thereto. A report of the chemical analysis of the blood, which indicated intoxication, was admitted in evidence over objection at petitioner's trial for driving while intoxicated. Petitioner was convicted, and the conviction was affirmed by the appellate court, which rejected his claims of denial of due process, of his privilege against self-incrimination, of his right to counsel, and of his right not to be subjected to unreasonable searches and seizures". (https://supreme.justia.com/cases/federal/us/384/757/case.html)

${ }^{9}$ Confira-se a obra de Morton J. Horwitz, "The Warren Court and the pursuit of justice". New York: Hill and Wang, 1998.
}

http://revistasapereaude.org/index.php/edicoes/ano-5-volume-3-outubro-2016

D.O.I: 10.20523/sapereaude-ano5-vol-3-pg-1-25 
sangue do acusado era razoável, pois constituía um meio bastante preciso para determinar a intoxicação, ao mesmo tempo que não implicava praticamente nenhum risco, trauma ou dor, e foi realizado de uma maneira adequada por um médico, num hospital.

A opinião da Corte, redigida por Brennan, ressalta que o direito (privilege against selfincrimination) protege um acusado de ser compelido a testemunhar contra si mesmo, ou de outra forma fornecer ao Estado provas de natureza testemunhal ou comunicativa, e que a colheita e o exame de sangue não envolvem esse tipo de compulsão.

O voto de Brennan enfatiza que um ponto crítico da questão é se o acusado havia sido compelido a ser uma testemunha contra si mesmo ("to be a witness against himself"). E sublinhava que, a despeito de muitas constituições estaduais, inclusive a maioria das colônias originais, utilizarem uma redação que menciona não ser compelido a fornecer prova ("evidence") contra si mesmo, o fato é que a Quinta Emenda utilizava a palavra testemunha ("witness"). ${ }^{10}$

\subsection{South Dakota v. Neville (1983)}

Em 1983, no caso South Dakota v. Neville, a Suprema Corte complementou a orientação fixada em Schmerber, deixando claro que seria admissível como prova a recusa do acusado a submeter-se ao teste do bafômetro. Aqui, a redatora do acórdão foi a juíza Sandra O’Connor, que fez consignar em seu voto que em Schmerber ficou estabelecido o entendimento de que o Estado poderia forçar um acusado a se submeter ao teste de sangue sem violação ao direito contra a autoincriminação, ao passo que em South Dakota a Corte avançava na questão para também firmar

\footnotetext{
${ }^{10}$ A nota de rodapé n. 8 do voto do juiz Brennan está assim redigida: "Many state constitutions, including those of most of the original Colonies, phrase the privilege in terms of compelling a person to give "evidence" against himself. But our decision cannot turn on the Fifth Amendment's use of the word "witness." (...)" Conferir em: https://supreme.justia.com/cases/federal/us/384/757/case.html
} 
que a recusa do acusado em soprar o bafômetro poderia ser usada como prova no processo criminal, sem qualquer ofensa ao direito de não autoincriminação. ${ }^{11}$

\subsection{Missouri v. McNeely (2012)}

Em outubro de 2012, a Suprema Corte norte-americana voltou ao mesmo tema no caso Missouri v. McNeely. O caso foi resumido no acórdão nos seguintes termos:

"McNeely foi parado por um policial do Missouri por dirigir acima da velocidade e cruzar a faixa central da rodovia. Depois de se recusar a soprar no bafômetro para aferir a concentração de álcool em seu sangue, ele foi detido e levado para um exame de sangue num hospital próximo. O oficial em nenhum momento tentou providenciar um mandado. McNeely recusou consentimento ao teste de sangue, mas o policial ordenou ao técnico de laboratório que retirasse um amostra. O teste demonstrou que o nível de álcool estava bem acima do limite legal, e ele foi acusado de dirigir embriagado. Ele tentou anular o resultado do exame de sangue, alegando que a retirada dele sem um mandado violava os direitos assegurados na Quarta Emenda. (...)"

A questão jurídica em Missouri v. McNeely tocava diretamente a necessidade de mandado judicial para a retirada de sangue do acusado. O mérito da decisão de Schmerber v. California não revisitado, sequer remotamente. Mais de quarenta anos depois de uma votação apertadíssima de 5x4, a solução fixada em Schmerber v. California, ou seja, de que era lícita a colheita de sangue do motorista com suspeita de embriaguez, não foi posta em debate.

\footnotetext{
${ }^{11}$ O trecho do voto, no original: " Schmerber v. California, 384 U. S. 757 (1966), held that a State could force a defendant to submit to a blood alcohol test without violating the defendant's Fifth Amendment right against selfincrimination. We now address a question left open in Schmerber, supra, at 384 U. S. 765, n. 9, and hold that the admission into evidence of a defendant's refusal to submit to such a test likewise does not offend the right against selfincrimination". Conferir em: https://supreme. justia.com/cases/federal/us/459/553/
} 
O que se discutiu, em Missouri v. McNeely, foi apenas a necessidade de que a retirada de sangue seja autorizada, ou não, por mandado judicial. A Suprema Corte considerou que a mera dissipação do álcool no sangue não constituía, por si só, motivo que autorizasse a dispensa do mandado judicial. A autoridade policial deveria diligenciar esforços para obter um mandado judicial que autorizasse a coleta de sangue. Considerou-se que a autoridade policial estava dispensada de obter autorização judicial apenas quando as circunstâncias concretas do caso impedissem essa providência.

O precedente de 2012 serve como demonstração do grau de consolidação do entendimento jurisprudencial, nos Estados Unidos, acerca do contorno do princípio da não autoincriminação.

\section{JURISPRUDENCIA DA SUPREMA CoRTE NORTE-AMERICANA REFERENTE A PAPÉIS OU DOCUMENTOS NÃO ESTRITAMENTE PESSOAIS}

Como visto, nos crimes de trânsito a diferença entre as soluções jurisprudenciais no Brasil e nos Estados Unidos é notável. A compreensão do que se pode exigir do acusado, nos Estados Unidos, é completamente diversa da compreensão dominante no direito brasileiro, tanto na doutrina quanto na jurisprudência.

É difícil imaginar exemplo tão eloqüente, dessa diferença, do que a aceitação como prova em processo criminal de amostras de sangue retiradas sem o consentimento do acusado. É uma diferença de tratamento realmente dramática e deve surpreender quem está habituado à argumentação de nossa doutrina.

No entanto, o objetivo final de nossa reflexão é a colaboração do acusado com papéis e documentos, tal como previsto no art. 195 do Código Tributário Nacional. No que toca 
especificamente à produção de prova documental pelo acusado, alguns precedentes norteamericanos merecem atenção mais demorada.

\subsection{Wilson v. United States (1911)}

No caso Wilson v. United States, julgado em 1911, a Corte americana sustentou que a Quinta Emenda não protegia arquivos corporativos que estivessem na posse e no controle do presidente da empresa, ainda que tais documentos pudessem incriminá-lo. A Corte reconhecia que a Quinta Emenda indubitavelmente protegia o presidente contra a entrega compulsória de seus livros e papéis pessoais, mas, no tocante aos arquivos ou documentos corporativos, isso não acontecia.

Fez-se a distinção, em Wilson v. United States, da situação presente no julgamento de Boyd v. United States, ocorrido em 1886. Ao contrário do caso Boyd, onde os papéis eram privados, no caso Wilson eles possuíam natureza que os sujeitava ao escrutínio demandado pela investigação estatal. $^{12}$

\subsection{Bellis v. United States (1974)}

O caso Bellis v. United States, julgado em 1974, seguiu a mesma linha adotada no caso Wilson v. United States. Nesse precedente, a Corte entendeu que o sócio de uma pequena firma de advogados não poderia invocar o direito à não autoincriminação para justificar sua recusa em fornecer documentos financeiros da sociedade. Afirmou-se que a Quinta Emenda protege o indivíduo apenas de ser compelido a fornecer papéis pessoais. A garantia constitucional alcançaria apenas os arquivos comerciais do proprietário único ou do advogado único contendo informação mais íntima acerca da vida privada do indivíduo.

12 Confira-se o voto do juiz Brennan no caso Fisher v. United States em https://supreme.justia.com/cases/ federal/us/425/391/, no qual se faz esse cotejo e são extraídas essas conclusões. 
No caso Bellis, a Corte contemplava os precedentes no sentido de que a garantia constitucional seria inaplicável aos arquivos de uma pessoa jurídica. Pois os arquivos corporativos não contêm o elemento essencial de privacidade ou confidencialidade, a atrair a garantia constitucional. A ementa do acórdão possui o seguinte teor (tradução livre):

A garantia contra a autoincriminação, prevista na Quinta Emenda, não se aplica ao membro de uma sociedade de advogados dissolvida, que foi intimado para fornecer os livros e registros financeiros dessa sociedade, pois a sociedade, ainda que pequena, tinha uma identidade institucional (...). A garantia é limitada à sua histórica função de proteger apenas a pessoa natural de incriminação compulsória mediante seu próprio testemunho ou documentos pessoais. $^{13}$

\subsection{Fisher v. United States (1976)}

No caso Fisher v. United States temos uma situação ainda mais próxima às preocupações deste artigo, qual seja, o fornecimento de documentos relativos à tributação, utilizados como prova em processo criminal. O fatos do precedente, cujo acórdão foi redigido pelo juiz Byron White, podem ser resumidos nos seguintes termos (tradução livre):

"Em cada um desses casos os contribuintes, que estavam sob investigação por possível responsabilidade civil e criminal decorrente de lei federal do imposto de renda, depois de terem obtido de seus respectivos contadores

\footnotetext{
13 Confira-se a ementa, no original, em https://supreme.justia.com/cases/federal/us/417/85/: "Fifth Amendment privilege against self-incrimination held not available to member of dissolved law partnership who had been subpoenaed by a grand jury to produce the partnership's financial books and records, since the partnership, though small, had an institutional identity and petitioner held the records in a representative, not a personal, capacity. The privilege is "limited to its historic function of protecting only the natural individual from compulsory incrimination through his own testimony or personal records".
} 
documentos relacionados à preparação contábil de restituição de impostos, transferiram tais documentos para seus respectivos advogados, para que prestassem orientação legal aos contribuintes acerca dessas investigações. Em seguida, o Fisco requisitou que os advogados fornecessem os documentos, mas eles se recusaram a obedecer. O Governo, então, demandou a entrega forçada, que, em cada caso, foi ordenada pela Corte distrital. No No. 74-18 a Corte de Apelação manteve a decisão, considerando que os contribuintes não tinham adquirido um interesse possessório sobre os documentos e que os documentos não estariam imunes nas mãos dos advogados. Mas no No. 74-611 a Corte de Apelação reformou a decisão, sustentando que, em virtude da Quinta Emenda, os documentos estariam fora do alcance da atuação do Fisco se estivessem em poder do contribuinte, e assim, à luz da relação cliente-advogado, o contribuinte manteria esse privilégio mesmo depois de transferir essa documentação aos advogados. ${ }^{14}$

A Suprema Corte, também aqui, firmou a compreensão de que não haveria, nesses casos, violação da garantia constitucional à não autoincriminação. A ordem para que os advogados fornecessem os documentos não se enquadrava no conceito de ser compelido a testemunhar contra si mesmo.

\footnotetext{
14 A ementa do acórdão, no original, tem a seguinte redação: "In each of these cases taxpayers, who were under investigation for possible civil or criminal liability under the federal income tax laws, after having obtained from their respective accountants certain documents relating to the accountants' preparation of their tax returns, transferred the documents to their respective attorneys to assist the taxpayers in connection with the investigations. Subsequently, the Internal Revenue Service served summonses on the attorneys directing them to produce the documents, but the attorneys refused to comply. The Government then brought enforcement actions, and, in each case, the District Court ordered the summons enforced. In No. 74-18 the Court of Appeals affirmed, holding that the taxpayers had never acquired a possessory interest in the documents and that the documents were not immune from production in the attorney's hands. But in No. 74-611, the Court of Appeals reversed, holding that, by virtue of the Fifth Amendment, the documents would have been privileged from production pursuant to a summons directed to the taxpayer if he had retained possession, and that, in light of the attorney-client relationship, the taxpayer retained such privilege after transferring the documents to his attorney." Confira-se em https://supreme.justia.com/cases/federal/us/425/391/
} 
Afirmou-se expressamente que a Quinta Emenda não proscreve a produção compulsória de qualquer tipo de prova incriminatória, mas se aplica apenas quando o acusado é compelido a fazer uma comunicação testemunhal que o incrimina ${ }^{15}$. O fornecimento compulsório de documentação tributária, mesmo quando estiver evidente o interesse persecutório do Estado, não é vedado pela Quinta Emenda, pois ela não protege informação privada obtida sem um depoimento autoincriminatório compulsório, como é o caso de tal documentação.

\subsection{United States v. Doe (1984). ${ }^{16}$}

Durante uma investigação federal de corrupção envolvendo contratos públicos, um indivíduo titular de várias firmas individuais foi demandado a fornecer determinados registros negociais de suas várias empresas. A justiça federal de primeiro grau afirmou a imunidade de tais documentos (com exceção dos documentos para os quais houvesse exigência legal de que fossem preservados e permanecessem acessíveis a um órgão público), sob o fundamento de que o ato de fornecê-los envolveria autoincriminação de natureza testemunhal. O juízo de segundo grau manteve a decisão, afirmando que os registros estariam imunes, pois o ato de produzi-los ostentaria aspectos comunicacionais sob a proteção da Quinta Emenda.

\footnotetext{
15 Trecho do voto condutor, no original: "The Fifth Amendment does not independently proscribe the compelled production of every sort of incriminating evidence, but applies only when the accused is compelled to make a testimonial communication that is incriminating". Confira-se em https://supreme.justia.com/cases/federal/us/425/391/

${ }^{16}$ A ementa do acórdão resume os fatos nos seguintes termos: "During a federal grand jury investigation of corruption in the awarding of county and municipal contracts, subpoenas were served on respondent owner of sole proprietorships demanding production of certain business records of several of his companies. Respondent then filed a motion in Federal District Court seeking to quash the subpoenas. The District Court granted the motion (except as to records required by law to be kept or disclosed to a public agency), finding that the act of producing the records would involve testimonial self-incrimination. The Court of Appeals affirmed, holding that the records were privileged, that the act of producing them also would have "communicative aspects of its own" in that the turning over of the records to the grand jury would admit their existence, possession, and authenticity, and that hence respondent was entitled to assert his Fifth Amendment privilege against compelled self-incrimination rather than produce the records. The court further held that, in view of the Government's failure to make a formal request for use immunity under 18 U.S.C. $\$ \S 6002$ and 6003 , it was proper to reject the Government's attempt to compel delivery of the records". Confira-se em https://supreme.justia.com/cases/federal/us/465/605/
} 
A Suprema Corte, entretanto, avançando no entendimento já delineado no caso Fisher v. United States, afirmou que o fornecimento de tais documentos ou registros negociais eram obrigatórios, e não poderiam ser evitados sob o fundamento de ofensa ao princípio da não autoincriminação. O precedente estabelece que onde a elaboração de registros negociais é voluntária, nenhuma compulsoriedade está presente. A circunstância de que os registros estão na posse do indivíduo é irrelevante para determinar se a criação de tais registros foi compulsória.

A Juíza Sandra O’Connor, ainda que tenha integrado a maioria, fez questão de elaborar manifestação apenas para deixar explícito que o direito ao silêncio não prevê nenhuma proteção para conteúdos de papéis privados de qualquer tipo. ${ }^{17}$

O juiz Marshall, acompanhado por Brennan, fez questão de ressaltar sua divergência com a visão da juíza O’Connor, enfatizando que os documentos em questão seriam registros comerciais, o que implicaria um nível muito menor de relação com interesses privados como, por exemplo, os que estariam presentes num diário pessoal.

\subsection{Síntese dos precedentes.}

O exame panorâmico de todos esses precedentes torna evidente que a jurisprudência da Suprema Corte norte-americana empresta um significado muito restrito à garantia de não autoincriminação também no que se refere ao fornecimento de documentos por parte do acusado.

Para a Corte, não existe nenhum direito subjetivo de negar-se a fornecer documentos em seu poder, notadamente quando esses documentos não apresentam caráter estritamente pessoal. Vários

\footnotetext{
${ }^{17}$ Eis a passagem do voto da juíza O’Connor: "I write separately, however, just to make explicit what is implicit in the analysis of that opinion: that the Fifth Amendment provides absolutely no protection for the contents of private papers of any kind. The notion that the Fifth Amendment protects the privacy of papers originated in Boyd v. United States, 116

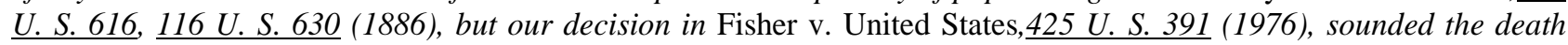
knell for Boyd". Numa tradução livre: "Eu escrevo separadamente, porém, apenas para tornar explícito o que está implícito na fundamentação do acórdão: que a Quinta Emenda não prevê absolutamente nenhuma proteção para conteúdos de papéis privados de qualquer tipo. A noção de que a Quinta Emenda protege a privacidade de papéis, surgiu em Boyd v. United States, mas nossa decisão em Fisher v. United States soa como uma morte anunciada para Boyd". Confira-se em https://supreme.justia.com/cases/federal/us/465/605/
}

http://revistasapereaude.org/index.php/edicoes/ano-5-volume-3-outubro-2016

D.O.I: 10.20523/sapereaude-ano5-vol-3-pg-1-25 
precedentes colocam ênfase, sobretudo, na possibilidade de exigir do cidadão a apresentação de documentos sem conteúdo estritamente pessoal. O direito de não produzir prova contra si mesmo alcança apenas a manifestação oral ou equivalente do acusado. A base para esse entendimento restrito é a própria redação da Quinta Emenda, a qual se refere apenas à impossibilidade jurídica de alguém ser testemunha contra si mesmo.

\section{A BASE NORMATIVA DO DIREITO AO SILÊNCIO NO DIREITO BRASILEIRO}

O direito ao silêncio está previsto no inciso LXIII do art. $5^{\circ}$ da Constituição, nos seguintes termos: "o preso será informado de seus direitos, entre os quais o de permanecer calado (...)".

A redação do dispositivo constitucional é bastante restrita. Em primeiro lugar, porque a Constituição utiliza o vocábulo "preso". E menciona apenas que ele tem o direito de permanecer "calado". Essas duas palavras remetem a situações bem delimitadas: a) uma pessoa sob a custódia do Estado; b) manifestação/comunicação oral ou equivalente.

A redação do dispositivo não menciona nenhum direito genérico de simplesmente não produzir prova contra si. Limita-se a enunciar que o preso tem direito a "permanecer calado". É preciso construir raciocínios mais sofisticados para se chegar à conclusão de que o preso ou acusado ou indivíduo em geral tem a seu favor um direito genérico de não fornecer provas ao Estado de cometimento de crime. Pois a Constituição, insista-se, menciona apenas o direito de ficar calado.

Contudo, no Brasil, a maioria da doutrina que se debruçou sobre o tema defende que o indivíduo possui um direito muito mais amplo do que apenas permanecer calado enquanto estiver sob a custódia do Estado, conferindo interpretação extensiva do inciso LXIII, ou extraindo de outros preceitos constitucionais a base desse direito mais abrangente, qual seja, o direito de não ser obrigado a colaborar para a própria condenação.

http://revistasapereaude.org/index.php/edicoes/ano-5-volume-3-outubro-2016

D.O.I: $10.20523 /$ sapereaude-ano5-vol-3-pg-1-25 
Sérgio Fernando Moro critica a posição que invoca o inciso LXIII como fundamento, por si só, para o reconhecimento de um amplo direito à não autoincriminação. ${ }^{18}$ Paulo Mário Canabarro Trois Neto concorda com a crítica de Moro $^{19}$, mas defende que "a norma que assegura uma posição individual de não colaboração do acusado em face do Estado-persecutor" pode ser extraída dos seguintes enunciados constitucionais: a) art. $1^{\circ}$, III (dignidade humana); b) art. $5^{\circ}$, LIV (devido processo legal); c) art. $5^{\circ}$, LV (ampla defesa); d) art. $5^{\circ}$, LVII (presunção de inocência). ${ }^{20}$

Maria Elizabeth Queijo também sustenta que o princípio nemo tenetur se detegere, entendido de forma mais ampla, e não apenas na específica manifestação do direito ao silêncio, pode ser extraído do princípio do devido processo legal, do direito à defesa, da presunção de inocência e da dignidade da pessoa humana. ${ }^{21}$ Ademais, para ela, os $\S \S 2^{\circ}$ e $3^{\circ}$ da Constituição Federal também seria fundamento normativo, pois o princípio está previsto no Pacto Internacional de Direitos Civis e Políticos e na Convenção Americana sobre Direitos Humanos, tratados internacionais que o Brasil ratificou em 1992. ${ }^{22}$ João Claudio Couceiro afirma que os direitos fundamentais são explicitações do princípio da dignidade da pessoa humana e, por consequiência, "também o direito ao silêncio encontra fundamento na proteção da dignidade da pessoa humana". ${ }^{23}$

\section{O DEVER DE COLABORAR COM O FISCO (ART. 195 DO CTN) E A GARANTIA DA NÃO} AUTOINCRIMINAÇÃO

\footnotetext{
${ }^{18}$ MORO, Sérgio Fernando. "Colheita compulsória de material genético para exame em casos criminais". Revista dos Tribunais, ano 95, volume 853, nov. 2006, p. 432.

${ }^{19}$ TROIS NETO, Paulo Mário Canabarro. Direito à não autoincriminação e direito ao silêncio. Porto Alegre: Livraria do Advogado Editora, 2010, p. 102.

${ }^{20}$ TROIS NETO, p. 104.

${ }^{21}$ QUEIJO, Maria Elizabeth. O direito de não produzir prova contra si mesmo: o princípio nemo tenetur se detegere e suas decorrências no processo penal. $2^{\mathrm{a}}$ ed. São Paulo: Saraiva, 2012, p. 93.

${ }^{22}$ QUEIJO, p. 90.

${ }^{23}$ COUCEIRO, João Claudio. A garantia constitucional do direito ao silêncio. São Paulo: Editora Revista dos Tribunais, 2004, p. 116.
}

http://revistasapereaude.org/index.php/edicoes/ano-5-volume-3-outubro-2016 
O art. 195 do Código Tributário Nacional impõe a obrigação inequívoca, a qualquer contribuinte, de dar à fiscalização tributária amplo acesso aos seus registros contábeis, bem como as mercadorias e os documentos respectivos. O preceito legal tem a seguinte redação:

Art. 195. Para os efeitos da legislação tributária, não têm aplicação quaisquer disposições legais excludentes ou limitativas do direito de examinar mercadorias, livros, arquivos, documentos, papéis e efeitos comerciais ou fiscais, dos comerciantes industriais ou produtores, ou da obrigação destes de exibi-los.

Parágrafo único. Os livros obrigatórios de escrituração comercial e fiscal e os comprovantes dos lançamentos neles efetuados serão conservados até que ocorra a prescrição dos créditos tributários decorrentes das operações a que se refiram.

Diante da redação do dispositivo legal, fica evidente que os contribuintes tem o dever de fornecer tais documentos ao fisco, quando solicitados: "obrigação destes de exibi-los". Mas essa exigência, que tem amparo legal, é constitucionalmente legítima ainda quando o fornecimento de tais documentos possa incriminar o contribuinte?

Se o direito à autoincriminação for entendido de forma dilatada, como vem sendo pela doutrina e jurisprudência brasileira, a conclusão inevitável pareceria lógica: o fornecimento desse material, na medida em que significaria uma colaboração do acusado com o Estado-acusador, resultaria em vulneração da garantia constitucional da não autoincriminação. Mas essa não parece ser, a nosso juízo, a solução mais correta.

Em primeiro lugar, a Constituição não contempla nenhum direito irrestrito de não produzir prova contra si mesmo. As palavras utilizadas pela Constituição possuem sentido literal bastante 
limitado. Não há dúvida de que a garantia do direito ao silêncio serve para proteger a dignidade da pessoa humana. Não se pode considerar que toda e qualquer colaboração do acusado seja tomada, $a$ priori e por si só, como ofensiva e atentatória à dignidade humana. É difícil perceber em que medida a dignidade da pessoa humana estaria sendo violada, na situação em que a pessoa é obrigada a fornecer livros ou documentos sob sua guarda, que foram produzidos sem qualquer violência física. E mais: quando esses papéis servem justamente para escrutínio público.

Não se pode perder de vista qual a finalidade e a razão de ser da garantia da não autoincriminação. João Claudio Couceiro, observa, muito acertadamente, que "o conteúdo essencial e inviolável do direito ao silêncio é a proteção à integridade física e mental da pessoa, de forma que toda limitação imposta por lei que não venha a afetá-la é legítima". ${ }^{24}$ A obrigação de fazer consistente em entregar documentos de conservação obrigatória não viola, à primeira vista, nem a integridade física, nem a integridade mental da pessoa.

É muito útil, nessa avaliação, notar que a Suprema Corte norte-americana sequer considera existente essa violação na hipótese de extração forçada de amostras sangüíneas. Como ficou demonstrado acerca da produção probatória nos crimes de trânsito, a coleta de uma amostra de sangue não importa praticamente nenhuma dor ou trauma. Se a extração do sangue do indivíduo não importa violação à garantia de não autoincriminação, porque a entrega de papéis normalmente ligados à atividade profissional do contribuinte significaria uma agressão dessa garantia?

Esses documentos foram produzidos sem qualquer ato de violência do Estado. A conservação de livros contábeis é um dever legal. Mas não se pode considerar que a mera existência de dever legal resultaria numa violência e numa agressão à pessoa. Do contrário, ninguém estaria vinculado a cumprir deveres impostos na lei, sob a alegação de que ser constrangido a cumprir a lei constituiria uma violência à liberdade e à dignidade humana.

${ }^{24}$ COUCEIRO, João Claudio. A garantia constitucional do direito ao silêncio. São Paulo: Editora Revista dos Tribunais, 2004, p. 131. 
Por outro lado, conforme indicam os vários precedentes da Suprema Corte norte-americana sobre o fornecimento de papéis comerciais, profissionais ou tributários, esse tipo de documentação não possui natureza pessoal, íntima, capaz de constituir um a invasão na esfera da vida íntima ou privada, que significa, no final de contas, na razão de ser da garantia processual. O contribuinte não pode aspirar, quando elabora tal documentação, um lugar de privacidade e intimidade para tais papéis, pois eles são produzidos, desde o começo, com a certeza de que estarão abertos ao escrutínio público. Ou, no mínimo, ao escrutínio do Fisco.

Não parece necessário sustentar, como faz Couceiro, que os livros fiscais não pertencem ao comerciante: "os livros fiscais não pertencem ao comerciante. tais livros são da Fazenda Pública, estando sob a guarda do comerciante, que ali deve registrar seu movimento. O comerciante é depositário de bem que pertence à Fazenda Pública. Logo, quando esta exige que o exiba, não tem ele, como mero depositário que é, o direito de recusa ${ }^{\prime 25}$ Basta admitir que não existe, como de fato não existe, no fornecimento de documentos de elaboração e conservação obrigatórias, qualquer agressão à dignidade da pessoa humana.

\section{CONCLUSÃO.}

O dever de colaboração imposto no art. 195 do Código Tributário Nacional não viola o princípio da não autoincriminação. A garantia constitucional não possui a latitude que atualmente lhe conferem a doutrina e a jurisprudência brasileiras. A Constituição brasileira, assim como a Constituição norte-americana, não assegura o direito genérico de não produzir prova contra si

\footnotetext{
${ }^{25}$ COUCEIRO, p. 349.
} 
mesmo, mas apenas um direito mais limitado de não ser obrigado a confessar, ou seja, de permanecer calado se assim desejar.

Os papéis comerciais ou fiscais dos comerciantes, industriais ou produtores, não dizem respeito à personalidade do possuidor deles, não constituindo, portanto, nenhuma violação da privacidade o acesso do Fisco a eles. Tais papéis comerciais ou fiscais são produzidos sem nenhum constrangimento ou ordem direta do Fisco, estando sua produção inteiramente sob a responsabilidade do contribuinte. O fornecimento dessa prova (documentos fiscais e comerciais) não demandam, para sua produção, o cometimento de nenhuma violência por parte do Fisco.

\section{BIBLIOGRAFIA}

COUCEIRO, João Claudio. A garantia constitucional do direito ao silêncio. São Paulo: Editora Revista dos Tribunais, 2004.

http://revistasapereaude.org/index.php/edicoes/ano-5-volume-3-outubro-2016 
HORWITZ, Morton J. "The Warren Court and the pursuit of justice". New York: Hill and Wang, 1998.

MORO, Sérgio Fernando. "Colheita compulsória de material genético para exame em casos criminais". Revista dos Tribunais, ano 95, volume 853, nov. 2006, p. 432.

QUEIJO, Maria Elizabeth. O direito de não produzir prova contra si mesmo: o princípio nemo tenetur se detegere e suas decorrências no processo penal. $2^{\mathrm{a}}$ ed. São Paulo: Saraiva, 2012.

TROIS NETO, Paulo Mário Canabarro. Direito à não autoincriminação e direito ao silêncio. Porto Alegre: Livraria do Advogado Editora, 2010.

TARUFFO, Michele. Uma simples verdade: o juiz e a construção dos fatos. São Paulo: Marcial Pons, 2012.

TOMÉ, Fabiana del Padre. A prova no direito tributário. $3^{\mathrm{a}}$ ed. São Paulo: Noeses, 2012. 